\title{
DISCURSO SOBRE ENSINO DE LÍNGUA PORTUGUESA NA UNIVERSIDADE: AS (DES)CONSTRUÇÕES DO IMAGINÁRIO DE ENSINO DE LÍNGUA EM GRADUAÇÃOO DE DIREITO
}

\author{
DISCOURSE ON PORTUGUESE LANGUAGE TEACHING AT UNIVERSITY: \\ POINTS TO THE IMAGINARY OF PORTUGUESE TEACHING IN LAW \\ UNDERGRADUATE COURSES
}

\author{
Mary $\mathcal{X}$ eiva Surdi $\mathcal{D} a \mathcal{L} z^{*}$ \\ Universidade Federal da Fronteira Sul, Chapecó, SC, Brasil \\ Rossaly Beatriz Chioquetta Lorenset** \\ Universidade do Oeste de Santa Catarina, Xanxerê, SC, Brasil
}

\begin{abstract}
Resumo: Este artigo investiga as (des) construções do imaginário de ensino de Língua Portuguesa no Ensino Superior em graduação de Direito, olhando para as vertentes de ensino e os saberes linguísticos mobilizados, à luz da Análise de Discurso (AD) da escola francesa, em diálogo com a História das Ideias Linguísticas (HIL). A partir de arquivo documental-institucional do Curso de Direito da Universidade do Oeste de Santa Catarina - Unoesc - Xanxerê, em 2000, ano da criação do curso, até 2013, abarcando as alterações do Projeto Pedagógico deste curso, analisam-se os ementários dos componentes curriculares de Língua Portuguesa e nomenclaturas congêneres de Português Aplicado ao Direito e Produção de Textos. A materialidade linguística que emergiu do corpus trouxe indícios de que há ecos e ressonâncias do imaginário de língua da historicidade do ensino de língua e da constituição do Ensino Superior no Brasil, de mais de dois séculos. Consideramos relevante que professores de Língua Portuguesa conheçam as práticas pedagógicas norteadas pela legislação, em distintos momentos históricos, bem como a ideologia que as sustentam, de forma a contribuir acerca das reflexões em torno do discurso sobre (MARIANI, 1998; ORLANDI, 2008; VENTURINI, 2009) 0 ensino de Língua Portuguesa na Educação Superior e seus modos de disciplinarização.
\end{abstract}

Palavras-chave: Ensino de língua portuguesa em graduação de Direito; imaginário de língua; língua imaginária; memória; Análise de discurso.

Abstract: This article studies the discourse about (MARIANI, 1998; ORLANDI, 2008; VENTURINI, 2009) the teaching of Portu-
guese in Higher Education in Law undergraduate courses, with the bond of theoretical assumptions of Discourse Analysis of Peuchet's
French strand in dialogue with Linguistic Ideas History: a path that provides an analysis of the language's imaginary, issues of
education and language knowledge organized in higher education. Starting at documentary-institutional file, memorandum books of
curriculum components of Portuguese Language are analyzed through the study of the Law Course Creation Project of the Universidade
do Oeste de Santa Catarina - Unoesc Xanxerê, in 2000, the year of creation of the course, until 2013, and also encompasses the
study of reformulations on the Project and Pedagogical Degree Plan. These documents constitute this research corpus and assist the
understanding of the language knowledge that work in formulating Portuguese curriculum components. Regarding the curriculum

* Professora doutora da Universidade Federal da Fronteira Sul - UFFS, Chapecó, SC, Brasil; neivadaluz@gmail.com

** Professora mestre da Universidade do Oeste de Santa Catarina - UNOESC, Xanxerê, SC, Brasil; professora.rossaly@gmail.com 
Linha D'Água (Online), São Paulo, v. 29, n. 1, p. 225-242, jun. 2016

components' memorandum books of language teaching through the discursive functioning presented in linguistic materiality, it is observed that they are not self-excluding and which points to the imaginary of Portuguese teaching. Several aspects and issues emerge, assisting to deepen the debate about the discourse on Portuguese teaching in higher education and its modes of discipline.

Keywords: Discourse Analysis; Language's imaginary; Portuguese Teaching in Law Degree; Imaginary language; Memory.

\title{
Introdução
}

\author{
A linguagem \\ na ponta da língua, \\ tão fácil de falar \\ e de entender.
}
A linguagem
na superfície estrelada de letras,
sabe lá o que ela quer dizer?
$[\ldots]$
O português são dois; o outro, mistério.
(ANDRADE, Carlos Drummond de, 1974, p. 76).

Iniciamos pelas palavras da epígrafe de Carlos Drummond de Andrade (Ibid.) que, em linguagem poética, sugere a reflexão de que há uma Língua Portuguesa que está na "ponta da língua", fácil de falar e de entender e há uma outra Língua Portuguesa, a da escola, a da universidade, incompreensível: "sabe lá o que ela quer dizer? ”E, com essa percepção, há o "mistério", o imaginário, o estranhamento da língua.

Neste enleio de "mistério" e de imaginário, apresentamos a questão que norteia nossa análise e reflexão neste estudo: que imaginário de ensino de língua emerge do fio do discurso de documentos institucionais, materializado nos ementários dos componentes curriculares de Língua Portuguesa do curso de graduação em Direito da Universidade do Oeste de Santa Catarina - campus de Xanxerế${ }^{1}$ ? Sob

Em 1968 foi criada, em Joaçaba SC, a primeira fundação educacional da região oeste de Santa Catarina. Esta foi a gênese da Universidade do Oeste de Santa Catarina, Instituição de Ensino Superior, privada, sem fins lucrativos, comunitária, que já formou mais de 30 mil profissionais e possui unidades nas cidades catarinenses de Campos Novos, Capinzal, Chapecó, Fraiburgo, Joaçaba, Maravilha, Pinhalzinho, São José do Cedro, São Miguel do Oeste, Videira e Xanxerê. Disponível em: <http:// www.unoesc.edu.br>. 
Linha D'Água (Online), São Paulo, v. 29, n. 1, p. 225-242, jun. 2016

a perspectiva teórico-metodológica da Análise de Discurso ${ }^{2}$ - fundada nos trabalhos de Michel Pêcheux e Eni Orlandi - e da História das Ideias Linguísticas $^{3}$ entendemos que imaginário é constante movimento, (res)significação, muito embora possua regularidades em uma discursividade dominante: o imaginário parece fechado, mas não o é, pois, pela porosidade da língua, há entradas, há deslizes, como processo de significações ideologicamente constituído. Foi no movimento analítico que "ousamos" atravessar o imaginário que interpela os sujeitos em suas discursividades e compreender o que está sendo dito a partir do modo como os sentidos estão sendo produzidos. $\mathrm{O}$ mecanismo imaginário produz imagens dos sujeitos assim como do objeto do discurso em uma conjuntura histórica. Nesse sentido, tecemos, nas páginas deste artigo, a trama do imaginário de ensino de língua ao dar visibilidade à língua imaginária, que não é estanque, mas possui as sistematizações e coerções das regularidades discursivas dominantes.

\section{1 (D)o lugar da língua portuguesa em curso de Direito: a tessitura do gesto analítico de mãos dadas com o fio teórico}

É preciso escutar "os rumores dos discursos", sem a preocupação de encontrar o que é ideal ou perfeito, mas considerando que a superfície do discurso possa ser o depositário de uma beleza também específica. (PETRI, 2013, p. 45).

\footnotetext{
2 A Análise do Discurso é um campo de saber específico, contudo, dialoga com a Linguística, pois, para o seu fundador, o francês Michel Pêcheux (2009, p. 18-19), faz-se mister tocar o triplo real da língua, da história, do inconsciente "[...] que se habitem e se habituem uns com os outros. "Para Ferreira (2001, p. 9-10), a Análise de Discurso propõe um deslocamento nas noções de linguagem, sujeito e ideologia: entende "[...] a linguagem enquanto produção social, considerando-se a exterioridade como constitutiva. $O$ sujeito deixa de ser centro e origem do seu discurso para ser entendido como uma construção polifônica, lugar de significação historicamente constituído."

3 A História das Ideias Linguísticas (HIL) inicia no Brasil, em 1987, com um projeto entre a Universidade de Paris 7 e a Universidade Estadual de Campinas (Unicamp). Para Nunes (2008), a HIL historiciza-se no Brasil sob o aporte dos trabalhos de Sylvain Auroux desenvolvidos na França e trabalhos de pesquisadores liderados por Eni Orlandi (2001), o que resultou na obra intitulada História das ideias linguísticas: construção do saber metalinguístico e constituição da língua nacional. Esse programa de pesquisa objetivava aliar a história da construção do saber metalinguístico com a história da constituição da língua nacional, contribuindo com o modo de pensar e de trabalhar as questões de língua. Assim, na base da história da produção de ideias linguísticas estão compreendidos instrumentos tecnológicos como gramática e dicionários e, no Brasil, a singularidade do processo de constituição da língua nacional.
} 
Neste artigo, tecemos nosso gesto de interpretação pela trama dos fios de nosso objeto de estudo, o discurso sobre $e^{4}$ o ensino de Língua Portuguesa em graduação de Direito, buscando "escutar os rumores do discurso", já que na mesma perspectiva da autora da epígrafe acima, para Rancière (2009, p. 21) "uma superfície não é simplesmente uma composição geométrica de linhas. É uma forma de partilha do sensível." Desse modo, mobilizamos analiticamente dois movimentos para escutar os rumores da "superfície" do discurso do corpus de nosso objeto de estudo: i) com base no estudo da historicidade e da memória discursiva ${ }^{5}$, enlaçados na filiação teórica da Análise de Discurso e História das Ideias Linguísticas, buscando compreender o objeto de nosso estudo no percurso de constituição da Língua Portuguesa no Brasil, também nos paradigmas que percorrem a constituição do Ensino Superior e do curso de Direito em nosso país e refletir sobre o papel do ensino de língua, observando-se os modos de circulação de saberes; ii) as vertentes de ensino de língua, de acordo com Camargo (2009), cujos estudos são da perspectiva da Educação, no entendimento de que a área da linguagem parece nortear-se por razões e concepções diversas e estabelecem-se três vertentes de ensino de língua como predominantes nessa prática: 1. reparadora ou supletiva; 2. instrumental ou tecnicista e 3. discursivo-textual.

Para sublinhar a metodologia teórico-analítica da Análise de Discurso, trazemos em foco a metáfora do pêndulo (PETRI, 2013, p. 44), pois, como analistas

4 Entende-se o discurso sobre a partir das proposições de Mariani (1998, p. 64, grifo do autor). "Os discursos sobre são os discursos que atuam na institucionalização dos sentidos, portanto, no efeito de linearidade e homogeneidade da memória. Os discursos sobre são discursos intermediários, pois ao falarem sobre um discurso de ('discurso-origem'), situam-se entre este e o interlocutor, qualquer que seja [...] já que o falar sobre transita na correlação entre o narrar/ descrever um acontecimento singular, estabelecendo sua relação com um campo de saberes já reconhecido pelo interlocutor." Depreende-se sentidos para esta noção também em Venturini (2009) e Orlandi (2008, p. 44): "Consideramos que 'os discursos sobre' são uma das formas cruciais da institucionalização dos sentidos. É no 'discurso sobre' que se trabalha o conceito da polifonia. Ou seja, o 'discurso sobre' é um lugar importante para organizar as diferentes vozes". E, especificamente no que toca nesse artigo, a autora ainda complementa afirmando que "O mesmo se passa com o discurso sobre o Brasil (no domínio da história). Ele organiza, disciplina a memória e a reduz."

5 Sem a inscrição da língua na história (memória) não há significação. Pensando a memória discursivamente, considera-se que seja "[...] aquilo que fala antes, em outro lugar, independentemente" (ORLANDI, 2012, p. 31, grifo nosso). A memória discursiva pode ser tratada, em alguns aspectos, como o interdiscurso. Concorda-se com Orlandi (2012, p. 31 , grifo nosso) que o que se chama de memória discursiva é "[...] o saber discursivo que torna possível todo dizer e que retorna sob a forma do pré-construído, o já dito que está na base do dizível, sustentando cada tomada da palavra." 
Linha D'Água (Online), São Paulo, v. 29, n. 1, p. 225-242, jun. 2016

de discurso, trabalhamos da perspectiva de quem lê diferentes materialidades: é uma leitura em movimento, pela mobilização das noções teórico-analíticas sobre um corpus, contribuindo para explicitar como se dão os processos de produção de sentidos. De acordo com a autora (Ibid., loc. cit.), o gesto de ler em Análise de Discurso implica também o gesto de escrever: e a escrita é fundamental para nos dar a medida do que conseguimos e do que não conseguimos compreender/ dizer na situação de análise, a qual nunca terminamos, somente a deixamos em suspenso. Complementa a autora (Ibid.), que é importante abrir e fechar a análise, demonstrando qual é a abrangência do recorte e que é imprescindível que o dispositivo teórico-analítico esteja descrito. Lemos, com a autora (Ibid., p. 46), que para compreender a produção dos sentidos do espaço discursivo, sem se render aos efeitos sedutores das evidências que são postas, relaciona o trabalho de analista de discurso ao de uma escultura de pedestal:

Faz-se necessário utilizar o espaço tridimensional, tal como faz o escultor; nela o objeto transcende o objeto visível, essa transcendência submete o objeto à condição de opacidade, na qual o óbvio não passa de um efeito de evidência facilmente desconstruído, nela a arquitetura faz parte da obra, há uma integração com o espaço, e isso altera os sentidos que dali se depreendem. (Ibid. loc. cit.).

Desse modo, a partir da perspectiva desta citação, passamos a compreender as possibilidades de relação entre funcionamento do discurso da Análise de Discurso e as intervenções políticas que se produzem, pois entendemos que a política e a arte, tanto quanto os saberes, "constroem rearranjos materiais das relações entre o que se vê e o que se diz, entre o que se faz e o que se pode fazer" (RANCIÈRE, 2009 , p. 59). No movimento pendular do processo de análise de nosso objeto, compreendemos que "para analisar o discurso é preciso pensar o acontecimento, não a criação; pensar as séries, não a unidade; pensar a regularidade, não a originalidade; pensar as condições de possibilidade, não a significação" (SCHONS; DAGNEZE, 2011, p. 44). Ainda consoante Petri (2013, p. 47), instalado o gesto de ler do analista no interior da discursividade que lhe interessa analisar, por um instante, $o$ analista suspende o pêndulo - ponto zero - e então começa o movimento, da teoria para a análise, "perpassando de diferentes maneiras os elementos constitutivos do corpus, com suas opacidades, com suas resistências, com suas porosidades, com sua densidade, com sua incompletude constitutiva”. Nesta perspectiva, interessa em nosso trabalho tomar o discurso em sua materialidade na língua e observar como se dá a produção de sentidos no encontro do histórico com o linguístico: nas palavras de Pêcheux (2012), no batimento entre a estrutura e o acontecimento, no 
Linha D'Água (Online), São Paulo, v. 29, n. 1, p. 225-242, jun. 2016

espaço do funcionamento da memória, que retoma e reconstrói, afinal, "é pelo discurso que a história deixa de ser vista apenas como evolução” (FERREIRA, 2001, p. 14). Assim, pelo delineamento de regularidades, alinhavamos a constituição de recortes discursivos que colocam em funcionamento diferentes efeitos de sentido na relação entre os saberes linguísticos em circulação em um curso de Direito, atravessados pelas marcas da memória da historicidade do ensino de língua e observando a predominância das vertentes de ensino de língua.

\section{2 (Entre)laçando os fios: memória, historicidade, língua imaginária no imaginário de língua do/no Direito}

[...] é absolutamente impossível encontrar um puro "discurso científico" sem ligação com alguma ideologia. (PÊCHEUX, 2009, p. 182).

Buscando (entre)laçar os fios da língua imaginária no imaginário de língua do/no Direito, entendemos com Zandwais (2012), que

as classes hegemônicas, ao se identificarem com a língua, passam a representá-la. Ao modo como constroem um imaginário de língua homogênea que, ao representar seus interesses, as representa, que lhes permite aprofundar as distâncias em relação às demais classes; enfim, que se torna útil à exclusão social dos linguisticamente desaparelhados, na medida em que refrata o fato de que uma mesma língua pode converter-se em muitas nas sociedades de classes. (Ibid., p. 179).

E é pensando na construção-(des)construção de um possível imaginário de língua homogênea que, ao representar interesses de classe hegemônicas pode excluir outras classes "desaparelhadas linguisticamente" que tecemos o gesto interpretativo analítico em dois movimentos que se mesclam: i) interpretando as materialidades linguísticas que emergem do corpus, pelo Recorte Discursivo (RD), olhando para as imagens construídas pelas relações histórico-ideológicas que determinam e constituem o imaginário de língua no/do Direito; ii) alinhavando os fios do funcionamento discursivo com os fios teóricos da Análise de Discurso. Antes, apresentamos o quadro RD e as Sequências Didáticas (SDs) que o compõem, cuja ilustração pode auxiliar na compreensão deste núcleo temático. 
Linha D'Água (Online), São Paulo, v. 29, n. 1, p. 225-242, jun. 2016

\section{(RD 6): A LÍNGUA IMAGINÁRIA NO IMAGINÁRIO DE LÍNGUA DO/NO DIREITO}

SD 1: Língua Portuguesa I: Introdução à comunicação para leitura. Análise e interpretação de textos. As várias possibilidades de leitura de um texto. O código ortográfico. Vícios de linguagem. Regência verbal. (2000;2003).

SD 2: Língua Portuguesa II: Vocabulário jurídico. Locuções latinas. Estilística e redação jurídica.A estrutura frásica na linguagem jurídica. Enunciação e discurso jurídico. O discurso dissertativo de caráter científico. (2000).

SD 3: Produção de Texto: Vocabulário jurídico. Locuções latinas. Estilística e redação jurídica. A estrutura frásica na linguagem jurídica.Enunciação e discurso jurídico. O discurso dissertativo de caráter científico. (2003).

SD 4: Produção de Texto: Leitura, interpretação, compreensão, análise e síntese de textos. O discurso oral. Vocabulário jurídico. Enunciação e discurso jurídico. O discurso dissertativo de caráter científico. Pontuação. Dificuldades lingüísticas mais frequentes na Língua Portuguesa. [sic] Concordância e regência nominal e verbal. (2004; 2005).

SD 5: Produção de Texto: Comunicação: elementos do processo. Signo: significante e significado. Texto: noção de texto, contexto, intertexto e gêneros textuais. Elementos coesivos. Coesão e coerência. Pontuação. Estudo do pronome. Dificuldades mais freqüentes da Língua Portuguesa. [sic] Leitura, compreensão, interpretação, análise e síntese de textos. Produção de textos descritivos, narrativos e dissertativos que contemplem as especificidades da área de formação. (2007).

SD 6: Português Aplicado ao Direito: Vocabulário jurídico. Estilística e redação jurídica. A estrutura frásica na linguagem jurídica. Enunciação e discurso jurídico. (2007).

SD 7: Produção de Texto: Leitura, interpretação, compreensão, análise e síntese de textos. O discurso oral. Vocabulário jurídico. Enunciação e discurso jurídico. O discurso dissertativo de caráter científico. Pontuação. Dificuldades lingüísticas mais freqüentes na Língua Portuguesa. [sic] Concordância e regência nominal e verbal. (2012).

SD 8: Produção de Texto: Leitura, compreensão, interpretação, análise e síntese de textos. Comunicação: elementos do processo. Signo: significante, significado: denotação, conotação, sinônimos, parônimos. Texto: noção de texto, contexto, intertexto, hipertexto e gêneros textuais. Elementos coesivos. Coesão e coerência. Pontuação. Estudo dos pronomes de tratamento e demonstrativos. Dificuldades mais frequentes da Língua Portuguesa: ortografia, concordância nominal e verbal, regência nominal e verbal, crase, colocação pronominal. Produção de textos de variados gêneros, contemplando estruturas descritivas, narrativas e dissertativas de acordo com a área de formação. (2013).

SD 9: Português Aplicado ao Direito: Processo de formação de palavras. Vocabulário jurídico. Estilística e redação jurídica. A estrutura frásica na linguagem jurídica. A organização do parágrafo. Enunciação e discurso jurídico. Oratória. (2013).

Figura 1: RD - A língua imaginária no imaginário de língua do/no Direito

Fonte: Elaborado pela autora.

Conforme nos mostra Pêcheux (2009), a prática discursiva é a forma como a prática política se materializa no domínio simbólico da linguagem: em Análise de Discurso, a seleção de sequências discursivas já é reveladora do encaminhamento de resultados do gesto analítico, pois esta seleção, concretizada em recortes da materialidade do corpus compreendido pelos documentos institucionais - $\mathrm{PPCDs}^{6}$ - do curso em graduação em Direito da Unoesc Xanxerê, já é resultado de um percurso de trabalho "em espiral" (PÊCHEUX, 2010, p. 312) que passa pela consideração das condições de produção, da interdiscursividade, da confirmação ou não de

- Plano Pedagógico do Curso de Direito.

SURDI DA LUZ, M. N.; LORENSET, R. B. C. Discurso sobre ensino de língua portuguesa 
Linha D'Água (Online), São Paulo, v. 29, n. 1, p. 225-242, jun. 2016

hipóteses, da busca extenuante das marcas linguísticas, entre outros componentes do método de análise da Análise de Discurso.

E no enredamento do trabalho "em espiral", trazemos uma materialidade linguística que margeia o corpus de nosso estudo, está à deriva, é uma ausência-presença e é possível que contribua para ilustrar este núcleo temático:

Diagnosticada a mazela, põe-se a querela a avocar o poliglotismo. A solvência, a
nosso sentir, divorcia-se de qualquer iniciativa legiferante. Viceja na dialética me-
ditabunda, ao inverso da almejada simplicidade teleológica, semiótica e sintática, a
rabulegência tautológica, transfigurada em plurilinguismo ululante indecifrável. Na
esteira trilhada, somam-se aberrantes neologismos insculpidos por arremedos do
insigne Guimarães Rosa, espalmados com o latinismo vituperante. [...] Portanto,
o hercúleo despendimento de esforços para o desaforamento do “juridiquês" deve
contemplar igualmente a magistratura, o ínclito Parquet, os doutos patronos das
partes, os corpos discentes e docentes do magistério das ciências jurídicas. (ASSO-
CIAÇÃO DOS MAGISTRADOS BRASILEIROS, 2007, p. 4).

O título do texto do excerto acima citado é "Entendeu?" Este subsídio auxilia a problematizarmos indagações que nos inquietam neste percurso epistemológico: de que Língua Portuguesa se trata aqui? A língua imaginária (ORLANDI, 2009), com suas coerções e sistematizações? Que especificidades apresenta? A técnica, a língua útil para o trabalho? Que imaginário permeia ou sustenta a Língua Portuguesa para o profissional do segmento jurídico? Daquele que tem "lábia”? Que língua é fundamental para o profissional do Direito? Nossa proposta é ir (des)atando e (entre)laçando os fios da língua imaginária no imaginário de língua do/no Direito e, no entretecer destas considerações, indicar possíveis caminhos para estas questões. O que nos conforta, ao transitar pelos saberes da Análise de Discurso, é que a incompletude é constitutiva e que algumas questões permanecem em aberto e requerem novas e ulteriores discussões. Buscando a compreensão destes fios, parece-nos que há ressonâncias do século XVI: lemos em Mariani (2004, p. 75) que, naquela época, havia um imaginário de superioridade de língua no sentido concedido à falta do $\mathrm{F}$, do $\mathrm{R}$ e do $\mathrm{L}$, legitimando a dominação do colonizador sobre a língua do colonizado, pois para o colonizador português, a religião, a realeza e o direito - três instituições nucleares do aparelho de Estado - simbolizavam um estágio avançado de civilização com base em uma única língua nacional gramatizada e escrita. Também ecoa de 1838 a forma histórica do sujeito social brasileiro que pode ser depreendida no modo como a língua é ensinada, notadamente em grandes colégios como o Colégio Pedro II: "no ensino da língua estão inscritos valores, 
Linha D'Água (Online), São Paulo, v. 29, n. 1, p. 225-242, jun. 2016

metas e perfis de formação de quadros para gerir nossas instituições e nossos projetos políticos de nação" (ORLANDI, 2013, p. 202).

Neste enredamento, conforme os fios da memória e da historicidade dos cursos de graduação em Direito, a $\mathrm{AMB}^{7}$, desde 2007, lançou uma campanha desafiadora para alterar a cultura linguística dominante da área do Direito e acabar com textos em intrincado juridiquês como o publicado acima. A importância da simplificação da linguagem jurídica é paradoxalmente "explicada" pelo emprego exagerado de expressões de difícil compreensão. Há um capítulo da obra (ORLANDI, 2013, p. 45) que traduz o "Juridiquês em (bom) português", que apresenta várias páginas com expressões latinas que são empregadas pelos profissionais do Direito cotidianamente e os respectivos significados. Também, este mesmo capítulo, apresenta um rol de 114 expressões jurídicas explicadas. Trouxemos aqui o fragmento acima para contribuir com a questão que nos move e com as reflexões acerca de que imaginário de língua emerge no fio do discurso de documentos institucionais, materializado nos ementários de componentes curriculares de ensino de Língua Portuguesa em um curso de graduação em Direito.

Se olharmos para o passado, observamos que, no Brasil, com o transcorrer dos séculos, foi construído imaginário de língua do segmento jurídico do bem dizer, da retórica persuasiva e convincente, da boa argumentação que remetem a estruturas, códigos e sistemas abstratos que não possuem relação alguma com a exterioridade. Tais imagens são presentificadas pelo excerto do texto da AMB, em pleno século XXI, é contemporâneo, não é um texto hermético, cheirando a pó, de séculos anteriores.

Uma das noções de língua da Análise de Discurso, conforme Orlandi (2009) e Lorenset (2013), é a de língua fluida, mutável, maleável, em constante (trans)formação e pela heterogeneidade constituída. Em sentido antagônico, contrariando esta fluidez, observamos a reprodução de discursos - como o esdrúxulo exemplo da AMB (2007) -, reduzindo a língua a um imaginário engaiolado por normas e restrições que acabam por amarrar um padrão de língua culta notadamente em relação à língua escrita, mais fácil de manter os padrões estanques e coercitivos, dito de outro modo, em que as mudanças não ocorrem de modo tão significativo quanto à língua falada. Nossa proposta aqui é discutir o fenômeno de manutenção do(s) discurso(s) que (re)produzem o imaginário de língua no/do Direito.

Temos a mesma ideologia de um imaginário de língua "ideal" sendo propagado por meio de discursos que (re)afirmam sua manutenção para assegurar a

7 Associação dos Magistrados Brasileiros. 
Linha D'Água (Online), São Paulo, v. 29, n. 1, p. 225-242, jun. 2016

dominância daqueles que se beneficiam deste imaginário de língua. No percurso da historicidade, as Faculdades de Direito, inicialmente, Ciências Jurídicas, foram instituindo práticas que se foram repetindo para fortalecer o imaginário de língua do/no Direito que distancia, inibe e exclui o falante da língua que corre solta pelas ruas ou, como prefere Zandwaiss (2012), aprofundar as distâncias em relação às demais classes, útil à exclusão social dos "linguisticamente desaparelhados", refratadas as condições concretas sob as quais ela funciona. Nesse sentido, de acordo com a autora (Ibid.) temos de considerar o fato de que um sujeito também é sujeito a partir do código que domina e se a "cartoralidade do Estado" transforma o plurilinguismo em monolinguismo, isso não ocorre sem consequências, pois o monolinguismo só pode ser representado a partir do imaginário de língua escrita.

E no movimento mais "em espiral" do que um vaivém pendular, vamos pontuando fios teóricos entrelaçados tanto com a historicidade quanto com a discursividade, corroborando o acima abordado, retomamos a reflexão de Pêcheux acerca de 'Língua de Estado, isto é, uma série de estratégias de discurso obstinada em evacuar qualquer contradição [...] o dizível e o existente devem coincidir sem falha nos enunciados" (PÊCHEUX, 2012, p. 86). Nesse sentido, para Mariani (2003), apoiada em Pêcheux (2009, p. 162), o imaginário linguístico é o lugar onde se encontra materializada a rede de paráfrases e formulações características de uma formação discursiva e "é no imaginário linguístico que o sujeito encontra refúgio enquanto ilusão necessária de sua unidade" (MARIANI, 2003, p. 56). Sob esse prisma, as representações imaginárias que os sujeitos constituem face às suas condições materiais de existência vão se naturalizando na história: "é um dizer historicamente circunscrito às redes de paráfrases, encadeamentos constitutivos dos processos de produção dos sentidos inerentes às formações discursivas e que garantem um efeito de literalidade para as representações imaginárias" (Ibid., p. 60-61).

Neste sentido, a própria pesquisadora foi interpelada pelas redes parafrásticas do sempre-já-lá, a analisar as SDs 5 e 8, em Signo: significante e significado. Pela estabilização dos sentidos, inicialmente, entendemos como concepção sistêmica de língua de Saussure (2012), contudo, ao desnaturalizar a relação palavra-coisa, conforme Orlandi (2012, p. 78) e Pêcheux (2009, p. 162), desfazendo a ilusão de que aquilo que foi dito só poderia ser daquela maneira e não de outra, ousamos deslocar para possíveis outros teóricos, buscando constituir uma rede de famílias parafrásticas que remetem a outros dizeres. Para a Análise de Discurso, a supremacia do significante sobre o significado deve ser compreendida em referência a uma dada formação discursiva. Pêcheux (Ibid., p. 164) retoma a questão do significante, pelas teorias de Lacan (1986;1998) e Althusser: (1985) o sujeito, quando diz "eu", o faz a partir de sua inscrição no simbólico e inserido em uma relação imaginária 
Linha D'Água (Online), São Paulo, v. 29, n. 1, p. 225-242, jun. 2016

com a realidade do que lhe é dado a ser, agir, pensar: "não há naturalidade do significante"(Ibid., loc. cit.). Se Pêcheux releu Lacan, por sua vez, conforme lemos em Mariani (2003) fez uma releitura crítica do objeto da linguística como sistema de signos constituídos por significados e significantes e, sobre o significante afirmou: "se pode dizer que é na cadeia do significante que o sentido insiste, mas que nenhum dos elementos da cadeia consiste na significação de que ele é capaz nesse momento"(LACAN apud MARIANI, 2003, p. 63). Tecemos esta abordagem porque o PPCD que contempla este ementário não traz Saussure (2012) nem como bibliografia básica, tampouco como bibliografia complementar, abrindo então a possibilidade de se trabalhar este ementário, por exemplo, sob a óptica lacaniana, ou pecheutiana: pela interpelação do já-lá, estabilizamos o sentido e, assujeitados, estabelecemos uma relação imaginária tão-somente possível à teoria saussureana ${ }^{8}$.

Ainda nesta esteira da interpelação, de acordo com e Pêcheux (2009) e Mariani (2003), o sujeito não se percebe preso em uma rede de linguagem, rede essa que o constituiu como sujeito antes de mais nada. Ele sofre os efeitos da interpelação-identificação ficando preso às evidências constituídas na própria linguagem: julga-se fonte dos próprios pensamentos, origem do próprio dizer, capaz de dominar o seu dizer e julga-se livre para dizer o que quiser. Neste entretecer de qual imaginário de língua emerge do intradiscurso ${ }^{9}$ dos ementários, não temos a pretensão de esgotar as análises de todas as materialidades linguísticas, mescladas, atravessadas, em coexistência nem sempre harmônica na heterogeneidade constitutiva. Destacamos os ementários da vertente de ensino com ênfase no caráter reparador, nas SDs 1, O código ortográfico. Vicios de linguagem. Regência verbal; nas SDs 5, 7 e 8, Pontuação. Dificuldades linguísticas mais frequentes na Lingua Portuguesa. Concordância e regência nominal e verbal; na SD 8, Estudo dos pronomes de tratamento e demonstrativos; na SD 9, Formação de palavras. O que está posto nestes ementários é o ensino de língua imaginária que Orlandi (2009) explica como construída por

8 Neste sentido de aclarar o porquê sublinhar, nas SDs 5 e 8, Signo: significante e significado, como análise pertinente à temática do imaginário neste RD6, de acordo com Zandwaiss (2012, p. 189), observamos que a construção de um imaginário, com evidências de que a língua seria uma realidade invariável, que permite representá-la por suas forças de imutabilidade pode ser identificada como um índice de alienação desde os pressupostos preconizados na obra Curso de Linguística Geral, de Saussure (2012), onde as forças de imutabilidade é que sustentem a construção de um imaginário de língua nas ciências da linguagem.

9 Segundo Pêcheux (2009, p. 153, grifo do autor), intradiscurso é o "[...] funcionamento do discurso com relação a si mesmo (o que eu digo agora com relação ao que eu disse antes e ao que eu direi depois; portanto, o conjunto dos fenômenos de 'co-referência' que garantem aquilo que se pode chamar o 'fio do discurso', enquanto discurso de um sujeito." 
Linha D'Água (Online), São Paulo, v. 29, n. 1, p. 225-242, jun. 2016

esquemas gramaticais rígidos, língua imaginária dos manuais, das gramáticas, dos dicionários, sem falhas, sem fissuras, sem deslizes é o "correto" bem-dizer versus o "errado", pressupõe o ensino tradicional, normativista, gramatical da língua.

Em nosso gesto epistemológico, alinhavamos também as SDs cuja predominância é a vertente de ensino com caráter instrumental, pragmático, tecnicista - a techné, nas SDs 2, 3, 6 e 9 em: Vocabulário jurídico. Locuções latinas. Estilistica e redação jurídica. A estrutura frásica na linguagem jurídica. Enunciação e discurso jurídico; na SD 7, O discurso oral .Enunciação e discurso jurídico; na SD 9, Oratória. São materialidades linguísticas que contribuem em muito para estabelecer e manter o imaginário linguístico do profissional do Direito, "de boa lábia”, persuasivo, com capacidade de boa argumentação. De acordo com Orlandi (2013, p. 68), "para ressoar é preciso forma material, a língua-e-a-história”. E nesse estudo em tela, a produção de sentidos se encontra inscrita numa rede de significantes "encarnados" (MARIANI, 2003, p. 68) historicamente, sofrendo os efeitos da tensão constitutiva do funcionamento da linguagem entre a paráfrase (já-dito antes, em outro lugar) e a polissemia (deslocamentos). E se as ressonâncias têm de ser materializadas, pontuamos a implantação dos cursos de Direito no Brasil e o prestígio dos profissionais da área porque o primeiro Estatuto das Universidades Brasileiras apontava, em seu bojo, que tinham de ter, dentre seis, pelo menos três cursos de graduação, entre eles, Direito. De acordo com autora (Ibid.), a determinação dos sentidos em termos históricos não deve ser entendida como cristalização eterna, pois, em sentido contrário à regularidade dominante do imaginário, nem a história, nem o inconsciente, nem a linguagem são imutáveis.

As materialidades linguísticas que auxiliam a construir e a manter um imaginário de língua no/do Direito, com ênfase bem mais no caráter textual e vestígios no caráter discursivo são: nas SD 4, 5, 7 e 8, Leitura, interpretação, compreensão, análise e sintese de textos; nas SDs 5 e 8, Texto: noção de texto, contexto, intertexto, bipertexto e gêneros textuais; Elementos coesivos. Coesão e coerência; na SD 9, A organização do parágrafo; e, por fim, as SDs 3, 4, 6, 7 e 9, Enunciação e discurso jurídico. Este último ementário, sob o viés instrumental, pragmático, aparece aqui não só para contribuir com a materialidade da pista linguística de discurso, como também para exemplificar que as vertentes de ensino estão atravessadas nas significações, se mesclam, se sobrepõem. Se investigamos que imaginário de língua emerge do fio de discurso dos PPCDs de Direito da Unoesc Xanxerê, há evidências de um imaginário de língua sob as teorias da enunciação, da linguística textual, da interação e da $\mathrm{AD}$, o imaginário de escrever bem, correto, com os elementos coesivos e coerentes contemplados. Imaginário!

Para Pêcheux (2009), na perspectiva discursiva, só é possível falar em imaginário com recurso ao simbólico, ao inconsciente e à ideologia. O simbólico é a 
Linha D'Água (Online), São Paulo, v. 29, n. 1, p. 225-242, jun. 2016

possibilidade da constituição do imaginário. $\mathrm{O}$ imaginário relaciona-se ao simbólico e possibilita a representação. O real, o simbólico e o imaginário são três registros distintos e fundamentais da realidade humana. Para a tessitura das reflexões de imaginário, trazemos o nó borromeano, formado por três anéis ou três círculos: Simbólico, Imaginário e Real. É a tripartição estrutural que, conforme Venturini (2008, p. 115), foi por Lacan concebido para mostrar a relevância e a interdependência entre uma e outra noção. Os três registros entrelaçam-se e coexistem, em relação de dependência direta entre si, ou seja, um não pode existir sem o outro: se um desses anéis fosse retirado, os outros ficariam soltos e perderiam a ligação que lhes é constitutiva. Foi em 1974 /1975 que Lacan se dedicou à questão dos três registros que compõem o funcionamento da cadeia significante: do real, do simbólico e do imaginário (na notação lacaniana, RSI, respectivamente). Nesse sentido, o Real define-se como impossível de ser simbolizado, impossível de ser transformado em discurso; o Simbólico entra em relação com o real e é responsável pelas transformações do sujeito e do discurso; o Imaginário relaciona-se ao simbólico e possibilita a representação.

Sobre a distinção entre real e imaginário, Orlandi (2012 p. 74) afirma que o "real do discurso é a descontinuidade, a dispersão, a incompletude, a falha, o equívoco, a contradição, constitutivas tanto do sujeito como do sentido". Em sentido antagônico, no imaginário "temos a unidade, a completude, a coerência, o claro e distinto, a não contradição” (Ibid., loc. cit.). É nesta articulação entre o real e imaginário que o discurso e a língua funcionam. "A demanda de que a língua não seja equívoca: esfera imaginária em que aquilo que permite satisfazer a demanda não tem outro alicerce além da própria demanda" (MILNER, 2012, p. 19).

Pelo posto nos ementários das $\mathrm{SDs}$ analisadas no $\mathrm{RD}$, compreende-se a língua como não sendo uma, inflexível, invariável, mas como fruto multifacetado, determinado pelas relações sociais, culturais e econômicas existentes. No segmento jurídico, o estudo da língua demanda de um olhar concomitante à sociedade, conforme vimos a campanha da Associação dos Magistrados Brasileiros - AMB - que preconiza a simplificação da linguagem do Direito com o objetivo inequívoco de aproximar o cidadão leigo do Judiciário. Esta inserção no ementário do componente curricular, de certa forma, contraria o que evidenciamos inicialmente, quando a SD8 prescreve a vertente de ensino com caráter reparador, como postura que tende a compreender a língua como um sistema de signos sujeitos à correção, a dicotomia 'certo x errado', ao normativismo, tendência que ainda impera no cenário educacional contemporâneo. Entendemos que o componente curricular Produção de Textos, da SD8, compreende os conhecimentos da língua e abarca as principais teorias da área, que dão conta de enfocar a língua(gem) sob pontos de vista distintos, porém não excludentes, 
Linha D'Água (Online), São Paulo, v. 29, n. 1, p. 225-242, jun. 2016

apenas diferenciados, tendo por base seu recorte científico e seu entendimento acerca de linguagem, língua, sujeito e sociedade.

\section{Conclusão}

A palavra é sangue e oxigênio para o advogado [...] É ferramenta de trabalho, arma de combate - porque não dizer - a sua própria vida [...] mesmo naqueles casos em que a redação é correta, 'falta o hálito da vida, o matiz da paixão, o lance crítico, que é condimento, espécie de salsa, dos trabalhos literários. Não é a palavra a nossa única arma? (PAULO FILHO, 1987, p. 163-164, grifo nosso).

Compreendemos com Bunzen (2011,p. 887) que as práticas escolares encontramse historicamente marcadas por movimentos de permanência, rupturas, deslocamentos, sedimentação, tensão e escolhas curriculares. Há aspectos históricos das propostas curriculares prescritas em documentos que se encontram inter-relacionadas com o ensino formal de língua, com fortes implicações na seleção dos saberes a serem escolarizados. Nas sequências discursivas analisadas e materializadas nas regularidades do quadro que abarca todos os ementários de componentes curriculares de ensino de língua de Direito da Unoesc, evidencia-se que há tensões produzidas nas relações entre vertentes de ensino e concepções de língua: essas tensões constituem a organização discursiva em que se produz o texto e o trabalho de análise da materialidade textual apresenta-se como um meio de observar e compreender os efeitos resultantes dessas tensões (PIETRI, 2007, p. 263).

Ancoramo-nos em Orlandi (2013) para mostrar aqui, nessa relação de universidade com o ensino de língua, essa oscilação contínua, essa imprecisão pedagógica que vai da erudição, da arte, da capacidade de instrumentação da vida intelectual à valorização do espírito ou à normatização do uso social ou ainda da afirmação de uma nacionalidade: intrincada história que não deixa de se tramar, sustentada pela relação entre 'empeiria' e 'tekhnẻ. Em que conhecimento e arte, ciência e saber se entrelimitam, dispondo sobre as relações que os sujeitos têm com a língua, consigo mesmos e com seus outros. (ORLANDI, 2013, p. 239).

Com a autora (Ibid.), retomamos a compreensão de que a língua do Direito é uma confluência dos três fins: aprende para a vida prática, aprende para ser especialista e aprende para ser artista da palavra, como orador, pois, na esfera jurídica, o ato de escrever é uma exigência profissional específica e se constitui em pré-requisito fundamental para o processo de formação de quaisquer carreiras jurídicas: advogados, defensores, procuradores, promotores, juízes e desembargadores. Com Pêcheux (2010, p. 314), deixamos em aberto a indagação: como conceber o 
Linha D'Água (Online), São Paulo, v. 29, n. 1, p. 225-242, jun. 2016

processo de uma $\mathrm{AD}$ numa interação "em espiral", combinando entrecruzamentos, reuniões e dissociações de séries textuais, de (des)construções de questões, de estruturações de redes de memória e de produções da escrita? "Ousamos" pensar que, nessa direção, alinhavamos aqui, neste artigo, entrecruzamentos de séries textuais da materialidade linguística dos ementários da graduação em Direito da Unoesc Xanxerê, com as (des)construções de questões que inquietam a pesquisadora, buscando compreensão nas condições de produção, nas redes de memória discursiva da historicidade do ensino de Língua Portuguesa no Brasil. A escrita deste estudo veio "escandir" este processo de uma Análise de Discurso "em espiral" produzindo um "efeito de interpretação" (Ibid., loc. cit.) que, conforme Pêcheux, já é uma tomada de posição.

E neste enredamento de imaginário de língua no/do Direito, efetuamos algumas considerações acerca do discurso sobre o ensino de Língua Portuguesa neste curso e pontuamos que as reflexões estão abertas, instigando novas pesquisas e discussões, pois, ao transitar pelos saberes da Análise de Discurso, entre inícios e reinícios, vamos edificando "instâncias de saber".(Nunes, 2011). Por derradeiro, com Lorenset (2014) pontuamos a reflexão: "é preciso suportar o que venha a ser pensado, isto é, é preciso ousar pensar por si mesmo,” (PÊCHEUX, 2009, p. 281) assim, ousamos desejar que a construção deste corpus e as reflexões aqui produzidas possam contribuir para suscitar olhares de outros pesquisadores acerca deste objeto de investigação.

\section{Referências}

ALTHUSSER, Louis. Aparelhos ideológicos do Estado: nota sobre os aparelhos ideológicos de Estado. Trad. Walter José Evangelista e Maria Laura Viveiros de Castro. Rio de Janeiro: Edições Graal, 1985.

ANDRADE, Carlos Drummond de. Procura de poesia. In: Reunião: 10 livros de poesia. 6 ed. Rio de Janeiro, José Olympio, 1974.

ASSOCIAÇÃO DOS MAGISTRADOS BRASILEIROS. O judiciário ao alcance de todos: noções básicas de juridiquês. 2 ed. Brasília: AMB, 2007.

AUROUX, Sylvain. A revolução tecnológica da gramatização. Trad. Eni Puccinelli Orlandi. Campinas, SP: Unicamp, 2009. 
Linha D'Água (Online), São Paulo, v. 29, n. 1, p. 225-242, jun. 2016

BUNZEN, Clecio. A fabricação da disciplina escolar Português. Revista Diálogo Educacional, Curitiba, v. 11, n. 34, p. 885-911, 2011.

CAMARGO, Márcio José Pereira de. Ensino de português em cursos superiores: razões e concepções. (2009). Dissertação (Mestrado em Educação). Programa de pós-graduação em Educação. Universidade de Sorocaba. Sorocaba, SP, 2009.

FERREIRA, Maria Cristina. Glossário de termos do discurso. (Org.). Porto Alegre: UFRGS, Instituto de Letras, 2001.

LACAN, Jacques. O seminário. Livro 1: os escritos técnicos de Freud, 1953-1954. Trad. Bety Milan. Rio de Janeiro: Jorge Zahar, 1986.

O seminário. Livro 11: os quatro conceitos fundamentais. 2 ed. Rio de Janeiro: Jorge Zahar, 1998.

LORENSET, Rossaly Beatriz Chioquetta. A noção de língua para a análise de discurso. In: Unoesc E̊ Ciência - ACHS, Joaçaba, v. 4, n. 2, p. 157-168, jul./dez. 2013.

. Componente curricular de língua portuguesa em curso de direito: uma análise de ementários. In: Unoesc E Ciência - ACHS, Joaçaba, v. 5, n. 1, p. 43-52, jan./jun. 2014.

MARIANI, Bethania Sampaio Corrêa. O PCB e a imprensa: os comunistas no imaginário dos jornais (1922-1989). Rio de Janeiro: Revan; Campinas: Ed. da Unicamp, 1998.

Subjetividade e imaginário linguístico. In: Linguagem em (Dis)curso, Tubarão, SC, v.3, Número Especial, p. 55-72, 2003.

. Colonização linguística. Campinas: Pontes, 2004.

MILNER, Jean-Claude. O amor da língua. Trad. Paulo Sérgio de Souza Júnior. Campinas, SP: Editora da Unicamp, 2012.

NUNES, José Horta. Uma revista de Língua Portuguesa: divulgação de saberes e silêncios. In: SHONS, Carme Regina; CAZARIN, Ercília Ana. (Orgs.). Lingua, escola e mídia: entrelaçando teorias, conceitos e metodologias. Passo Fundo: UPF Editora, 2011.

ORLANDI, Eni Puccinelli. Terra à Vista - discurso do confronto: velho e novo mundo. 2 ed. Campinas, SP: Editora da Unicamp, 2008.

Lingua brasileira e outras histórias: discurso sobre a língua e ensino no Brasil. Campinas: Editora RG, 2009. 
Linha D'Água (Online), São Paulo, v. 29, n. 1, p. 225-242, jun. 2016

Análise de discurso: princípios e procedimentos. 10 ed. Campinas, SP: Pontes Editores, 2012.

. Lingua e conhecimento linguístico: para uma história das ideias no Brasil. 2 ed. São Paulo: Cortez, 2013.

PAULO FILHO, Pedro. A revolução da palavra: uma visão do homo loquens. 2 ed. São Paulo: Siciliano, 1987.

PÊCHEUX, Michel. Semântica e discurso: uma crítica à afirmação do óbvio. Trad. Eni Pucinelli Orlandi. 4 ed. Campinas, SP: Editora da Unicamp, 2009.

. A análise de discurso: três épocas (1983). In: GADET, Françoise; HAK, Tony. (Orgs.). Por uma análise automática do discurso: uma introdução à obra de Michel Pêcheux. 4 ed. Campinas, SP: Editora da Unicamp, 2010, p. 307-315.

. Análise de discurso: Michel Pêcheux. Textos selecionados: Eni Puccinelli Orlandi. 3 ed. Campinas, SP: Pontes Editores, 2012.

PETRI, Verli. O funcionamento do movimento pendular próprio às análises discursivas na construção do "dispositivo experimental" da análise de discurso. In: PETRI, Verli; DIAS, Cristiane (Orgs.). Análise do discurso em perspectiva: teoria, método e análise. Santa Maria, RS: Editora da UFMS, 2013, p. 39-48.

PIETRI, Emerson de. Circulação de saberes e mediação institucional em documentos oficiais: análise de uma proposta curricular para o ensino de Língua Portuguesa. Currículo sem Fronteiras, v. 7, n. 1, p. 263-283, 2007.

RANCIÈRE, Jacques. A partilha do sensivel: estética e política. Trad. Mônica Costa Netto. São Paulo: EXO Experimental: Editora 34, 2009.

SAUSSURE, Ferdinand de. Curso de linguística geral. 34 ed. São Paulo: Cultrix, 2012.

SCHONS, Carme Regina; DAGNEZE, Cinara Sabadin. Trapaceando a língua no governo Médici: um estudo sobre o imaginário de língua pelo jornal O Pasquim. Linguagem em (Dis) curso, v. 11, n. 1, Tubarão, SC, p. 37-57, jan./abr. 2011.

SURDI DA LUZ, Mary Neiva. Linguística e ensino: discurso de entremeio na formação de professores de língua portuguesa. 2010. Tese (Doutorado em Letras). Programa de pós-graduação em Letras. Universidade Federal de Santa Maria. Santa Maria, RS, 2010. 
Linha D'Água (Online), São Paulo, v. 29, n. 1, p. 225-242, jun. 2016

UNIVERSIDADE DO OESTE DE SANTA CATARINA. Reitoria. Projeto de Aumento de Vagas do Curso de Bacharelado em Direito para o Campus de Xanxerê. (1999) Unoesc - Xanxerê/ SC. Xanxerê, 2000.

Projeto Pedagógico do Curso de Direito / Universidade do Oeste de Santa Catarina. UNOESC - Xanxerê, 2003.

Projeto Pedagógico do Curso de Direito / Universidade do Oeste de Santa Catarina. UNOESC - Xanxerê, 2004.

Projeto Pedagógico do Curso de Direito / Universidade do Oeste de Santa Catarina. UNOESC - Xanxerê, 2005.

Projeto Pedagógico do Curso de Direito / Universidade do Oeste de Santa Catarina. UNOESC - Xanxerê, 2007.

Reitoria. Processo de Renovação Reconhecimento do Curso de Direito oferecido pela Unoesc no Campus de Xanxerê. Universidade do Oeste de Santa Catarina. Joaçaba/SC: Unoesc, 2012.

. Reitoria. Projeto Pedagógico do Curso de Direito. Alterado pela RES.57 / CONSUN/2013 - em 12/06/2013. Joaçaba/SC: Unoesc, 2013.

VENTURINI, Maria Cleci. Imaginário urbano: espaço de rememoração/comemoração. Passo Fundo/RS: Editora UPF, 2009.

ZANDWAIS, Ana. Subjetividade, sentido e linguagem: desconstruindo o mito da homogeneidade da língua. In: ZANDWAIS, Ana. (Org.). História das ideias: diálogos entre linguagem, cultura e história. Passo Fundo: Ed. Universidade de Passo Fundo, 2012, p. 175-191.

Recebido em 11/04/2016

Aprovado em 29/05/2016 